\title{
Pengaruh Latihan Multiball Terhadap Keterampilan Smash Forehand Tenis Meja Pada Club Pade Angen Mataram Tahun 2020
}

\author{
${ }^{1}$ Nurdin, ${ }^{2}$ Aminullah \\ ${ }^{1}$ Fakultas Ilmu Keolahraga dan Kesehatan Masyarakat, Universitas Pendidikan Mandalika \\ ${ }^{2}$ Fakultas Ilmu Keolahragaan Dan Kesehatan Masyarakat, UNDIKMA \\ UNDIKMA Jalan Pemuda No. 59 A Gomong Mataram \\ nurdin@ikipmataram.ac.id ${ }^{1}$, aminsasaki@gmail.com ${ }^{2}$
}

\begin{abstract}
The focus of the problem in this study is that this research is motivated by the low accuracy of the forehand smash. Table tennis at Club Pade Angen Mataram in 2020. The research objectives to be achieved based on the predetermined problem formulation are as follows: To find out the effect of multiball training on the smash forehand table tennis skills at Club Pade Angen Mataram in 2020. The research design in use is an experimental research "One-Group Pretest-posttest Design". This experiment still has external variables that influence the formation of the dependent variable. So the experimental results which are the dependent variable (bound) are not merely influenced by the independent variable (free). Table Tennis Forehand Drive Accuracy Instrument To make it easier to understand below is a picture of a table marking sign of two targets on the right side of the testicle, namely the area of $30 \mathrm{~cm} \times 30 \mathrm{~cm}$, both of which are $60 \mathrm{~cm} \times 60 \mathrm{~cm}$. . Table Sampling technique using a population study of 12 players. Based on data analysis, getting the $t$ count obtained a value of 10.30 then the t-table with degrees of magnitude $N-1=11$ at a significant level of 5\% shows a number that is 1.796. This result means that the t-count>t-table, namely (3.995> 1.796) or in other words the t-count obtained is greater than the limit of the rejection of the null hypothesis $(\mathrm{Ho})$, it is necessary that the $t$-value is equal to or greater than the t value. -table.
\end{abstract}

Keywords: Exercise, multiball, smash forehand, table tennis

\section{ABSTRAK}

Fokus maslah dalam penelitian ini adalah Penelitian ini dilatarbelakangi oleh masih rendahnya kemampuan ketepatan pukulan smash forehand. tenis meja pada Club Pade Angen Mataram tahun 2020. Tujuan penelitian yang ingin di capai berdasarkan rumusan masalah yang telah ditetapkan adalah sebagai berikut: Untuk Mengetahui ada Pengaruh latihan multiball terhadap keterampilan smash forehand tenis meja pada Club Pade Angen Mataram tahun 2020. Rancangan Penelitian yang di gunakan adalah penelitian eksperimen "One-Group Pretest-posttest Desaign".Eksperimen ini masih terdapat variabel luar yang berpengaruh terhadap terbentuknya variabel terikat. Jadi hasil eksperimen yang merupakan variabel dependen (terikat) itu bukan semata-mata di pengaruhi oleh variable independen (bebas). Instrumen Ketepatan Pukulan Forehand Drive Tenis Meja Untuk mempermudah pemahaman dibawah ini adalah gambar tanda meja (table marking) tanda dua sasaran sebelah kanan testi yaitu luas $30 \mathrm{~cm} \times 30 \mathrm{~cm}$, kedua luasnya $60 \mathrm{~cm}$ x 60cm.Instrumen Ketepatan Forehand Drive Sumber: Tomoliyus (2012: 19). meja Teknik Pengambilan sampel menggunakan studi populasi yang berjumlah 12 pemain. Berdasarkan analisa data, mendapatkan t-hitung diperoleh nilai sebesar 10.30 kemudian t-tabel dengan derajat kebesaran $\mathrm{N}-1=11$ pada taraf signifikan 5\% menunjukan angka yaitu 1.796. Hasil ini berarti bahwa t- hitung > t-tabel, yaitu (3.995 > 1.796) atau dengan kata lain t-hitung yang diperoleh lebih besar dari angka batas penolakan hipotesis nihil (Ho) diperlukan nilai t-hitung sama atau lebih besar dari nilai t-tabel. 
Terakreditasi Peringkat 4 (No. SK: 36/E/KPT/2019)

Kata Kunci: Latihan, multiball, smash forehand, tenis meja

\section{PENDAHULUAN}

Tenis meja merupakan sebuah permaian yang sederhana. Gerakan-gerakan yang dilakukan dalam olahraga ini adalah konsisten memukul, mengarahkan dan menempatkan bola ke meja lawan dan diharapkan pihak lawan tidak dapat mengembalikan bola. Pada awalnya permainan ini menggunakan bola karet, kemudian menggunakan gabus dan karet tiruan (Salim, 2008:9)

Salah satu teknik pukulan yang penting dalam permainan tenis meja adalah smash forehand. Teknik ini perlu dikuasai oleh pemain, 3 bahkan menjadi satu teknik wajib yang harus dimiliki para pemain tenis meja. Kemampuan ketepatan smash forehand. berhubungan erat dengan kematangan dan frekuensi latihan. Artinya, untuk mendapatkan ketepatan smash forehand. yang baik, pemain harus berlatih dengan intensif dan terprogam. A.M Bandi Utama (2004: 3) mengatakan bahwa dalam pertandingan tenis meja, kemampuan ketepatan pukulan smash forehand. mempunyai peranan penting untuk memenangkan pertandingan. Smash forehand merupakan pukulan utama dalam permainan tenis meja.

Fokus maslah dalam penelitian ini adalah Penelitian ini dilatarbelakangi oleh masih rendahnya kemampuan ketepatan pukulan smash forehand. tenis meja pada Club Pade Angen Mataram tahun 2020. Dalam permainan tenis meja diperlukan pukulan yang tepat ke sasaran karena faktor dari ketepatan di dalam permainan tenis meja sangatlah penting guna untuk menempatkan bola yang sulit kearah yang susah dipukul lawan saat perlombaan. Oleh karena itu,pemain perlu mendapat latihan dalam menguasai teknik-teknik latihan yang ada dari guru atau pelatihnya. Kemampuan ketepatan pukulan smash forehand. berhubungan erat dengan kematangan dan frekuensi latihan. Artinya Penelitian ini bertujuan untuk mengetahui ada Pengaruh latihan multiball terhadap keterampilan smash forehand tenis meja pada Club Pade Angen Mataram tahun 2020.

Solusi yang diterapkan adalah latihan dalam tenis meja, menurut Larry Hodges (2007: 2) metode latihan dalam tenis meja antara lain berlatih dengan pemain lain, berlatih dengan pelatih, berlatih sendiri, mesin dan juga multiball. Dari berbagai metode dalam tenis meja, salah satu metode latihan yang digunakan untuk meningkatkan kemampuan ketepatan smash forehand. adalah "latihan multiball". Metode latihan ini menekankan pada frekuensi pemukulan, sehingga memungkinkan pemain untuk membiasakan diri memukul bola ke 4 sasaran yang dituju, sehingga gerakan mahasiswa tersebut menjadi otomatisasi Metode multiball bisa juga menggunakan mesin ataupun manual yang diberi oleh pelatih atau pengumpan. belum mempunyai mesin sehingga metode multiball secara manual sangatlah bagus untuk meningkatkan kemampuan ketepatan pukulan smash forehand.

\section{KAJIAN PUSTAKA}

\section{Latihan}

Kata Training, tidak selalu diartikan dengan latihan, meskipun seringkali digunakan secara bersamaan. Pada prinsipnya training olahraga merupakan suatu proses persiapan atlet untuk mencapai prestasi puncak atau terbaiknya. Dalam pengertian luas, training merupakan seluruh proses persiapan yang direncanakan secara teratur unuk merahi prestasi terbaiknya. (Syafruddin, 2011:23). 
Menurut Sukadianto (2005: 5) latihan adalah suatu kata yang sering dijumpai dengan istilah practice, exercise, dan training. Pengertian latihan dari kata practice adalah aktivitas untuk meningkatkan keterampilan (kemahiran) berolahraga dengan menggunakan berbagai peralatan sesuai dengan tujuan dan kebutuhan cabang olahraganya, artinya selama dalam kegiatan proses berlatih melatih agar dapat mengusai keterampilan gerak cabang olahraga selalu dibantu dengan menggunakan berbagai peralatan pendukung

\section{Multiball}

Metode dalam Kamus Besar Bahasa Indonesia adalah cara teratur yang diperlukan untuk melaksanakan suatu pekerjaan agar tercapai sesuai dengan yang dikehendaki. (Suharno, 1980:1) "Sedangkan metode dalam olahraga ialah cara melakukan sesuatu dengan runtut untuk menguasai bahan latihan agar menjadi otomatis gerakannya". Dari pengertian tersebut dapat disimpulkan bahwa metode adalah suatu cara yang telah dipilih secara sistematis berdasarkan analisis, pengalaman dengan membandingkan beberapa cara, sehingga didapat suatu kebulatan yang cocok untuk mencapai suatu tujuan yang efisien dan efektif.

Metode latihan yang dapat meningkatkan kemampuan teknik seorang pemain cukup bervariasi. Menurut Hodges (2007: 2) Multiball Ini adalah metode latihan di mana satu pemain berlatih sedang pemain yang lainnya mengumpankan bola. Pemain akan membutuhkan sekeranjang bola. Pemberi umpan berdiri di pinggir meja, memungut dan memukul bola berturutturut dalam berbagai kecepatan, putaran, dan arah yang pemain butuhkan. Metode ini merupakan cara yang tepat untuk mempelajari pukulan, tapi kerugiannya adalah hanya satu orang yang dapat berlatih pada saat itu. Metode ini sering digunakan oleh pelatih yang bertindak sebagai pengumpan. Tingginya frekuensi dengan teknik multiball diharapkan dapat membuat siswa terbiasa melakukan pukulan. Selama ini latihan dengan menggunakan metode multiball menjadi salah satu latihan yang digunakan guru atau pelatih. Salah satu tujuan latihan multiball tersebut adalah untuk meningkatkan kemampuan ketepatan pukulan forehand dan backhand siswa

\section{Forehand}

Pukulan forehand merupakan pukulan utama dalam permainan tenis meja. Menurut Sridadi (2004: 5), "kontrol bola forehand merupakan salah satu bentuk latihan pengenalan terhadap bola dan net". Pemain berusaha dengan pegangannya untuk menyentuhkan bet ke bola yaitu dengan cara memantulkan bola ke bet dalam hitungan waktu tertentu memantulkan bola dengan bet ini dapat dipantulkan atau dilambungkan. Tujuan dari latihan ini adalah agar seseorang pemain mampu mengontrol bola dengan pukulan forehand dengan baik dan sempuma. Pukulan forehand ini adalah salah satu bentuk pukulan dalam tenis meja yang arahnya sesuai dengan ayunan tangan. Oleh sebab itu, pukulan forehand sangat berpengaruh sekali terhadap kemampuan bermain seseorang.

\section{Tenis Meja}

Utama (2005:5) "permainan tenis meja adalah permainan dengan menggunakan fasilitas meja beserta peralatannya serta bet dan bola sebagai alatnya". Permainan ini diawali dengan pukulan pembuka (service), yaitu bola dipantulkan ke meja sendiri lalu melewati atas net dan memantul di meja lawan sampai lawan tidak dapat mengembalikan 
dengan baik. Pemain berusaha untuk mematikan pukulan lawan agar memperoleh angka dari pukulannya. Permainan tenis meja dapat dimainkan baik orang tua, remaja maupun anak-anak.

Sedangkan Hodges

(1996:1) "menjelaskan bahwa tenis meja adalah olahraga paling terkenal di dunia dan jumlah partisipasinya menempati urutan kedua". Tenis meja disebut juga pingpong. Pingpong adalah permainan dimana sebuah bola kecil yang putih dipukul bolakbalik hingga seseorang melakukan kesalahan. Berdasarkan beberapa pendapat para ahli di atas, dapat diambil kesimpulan bahwa permainan tenis meja merupakan suatu permainan yang menggunakan meja sebagai tempat untuk

\section{METODE PENELITIAN}

\section{Rancangan kegiatan}

Rancangan yang digunakan dalam penelitian ini adalah rancangan atau desain dengan model eksperimen. Yang dimaksud dengan metode penelitian eksperimen adalah suatu cara yang sistematis dan objektif untuk mencari hubungan sebab akibat antara dua variabel yang sengaja ditimbulkan oleh peneliti sebagai treatment secara ketat (Hulfian, 2014:9). Jadi segala yang diteliti dalam penelitian ini dilakukan dengan sengaja. Dimana dalam hal ini para pemain diberikan metode latihan 20 yard squared agar kelincahan pemain dapat meningkat. Semua dilakukan secara eksperimen.

Adapun rancangan penelitiannya adalah menggunakan One group pretestposttest design. Dalam desain ini tidak ada kelompok kontrol, dan subjek tidak ditempatkan secara acak. Kelebihan desain ini adalah dilakukan pretest dan posttest sehingga dapat diketahui dengan pasti perbedaan hasil akibat perlakuan yang diberikan.

\begin{tabular}{|c|c|c|}
\hline Pre-Tes & Tratment & Pos-Tes \\
\hline A1 & $\mathrm{X}$ & $\mathrm{A} 2$ \\
\hline
\end{tabular}

Gambar 1.1: The Static GroupPretestPostest Design, sumber

(Maksum, 2009:49)

Keterangan:

A1: Pre-test (tes smash forehand)

$\mathrm{X}_{1}$ : latihan multiball

A2: Post-test (tes smash forehand).

\section{Ruang lingkup}

Untuk mendapatkn data yang akurat sesuai dengan apa yang diinginkan maka, peneliti membatasi sebagai berikut:

a) Subyek penelitian Pada Pade Angen Mataram Tahun 2020.

b) Objek penelitian Metode latihan 20 Yard Squared. Variabel penelitian Macam-macam variabel dalam penelitian ini adalah sebagai berikut Variabel bebas (X) adalah variable yang mempengaruhi dalam penelitian ini adalah (X1) latihan multiball Sebagai variabel terikat adalah variabel yang dipengaruhui dalam penelitian ini adalah smash forehand.

\section{Bahan dan alat utama}

Untuk memperoleh data diperlukan alat pengukuran, yang dimaksud dengan instrumen adalah alat pada waktu penelitian dengan menggunakan suatu metode Arikunto (2013:192). Dalam penelitian ini peneliti mempersiapan pengumpulan data adalah memberikan pengertian kepada siswa tentang tes yang akan dilakukan. Tujuan persiapan pengumpulan data adalah untuk melakukan pengumpulan data disesuaikan dengan masalah yang ada. Dalam penelitian ini persiapan yang harus dilakukan adalah penyiapan alat-alat, penyiapan bahan, penyiapan peserta tes. 
Adapun petunjuk pelaksanaan tes adalah sebagai berikut: Alat-alat dan pelengkapan

1. bola tenis meja

2. bet

3. meja tenis

4. stopwatch

5. skor shet

Instrumen Ketepatan Pukulan

Forehand Drive Tenis Meja Untuk mempermudah pemahaman dibawah ini adalah gambar tanda meja (table marking) tanda dua sasaran sebelah kanan testi yaitu luas $30 \mathrm{~cm} \times 30 \mathrm{~cm}$, kedua luasnya $60 \mathrm{~cm} \times 60 \mathrm{~cm}$.

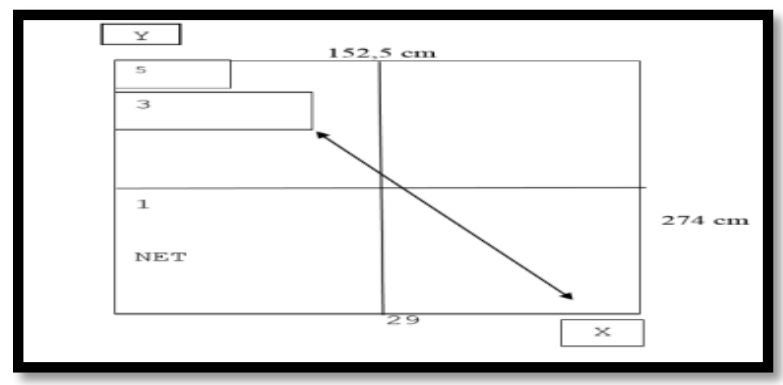

Gambar 1.2. Instrumen Ketepatan Forehand

Drive Sumber: Tomoliyus (2012: 19)

Keterangan :

$\mathrm{X}$ : testi

$\mathrm{Y}$ : pengumpan

1. Petunjuk tes:

Tahap pelaksanaan tes ketepatan

pukulan forehand drive:

a. Subjek disuruh melakukan pemanasan dan latihan (practice)

b. Bola pertama dimulai dari testi.

c. Subjek melakukan rally forehand drive diagonal selama 30 detik. Setelah istrahat 10 detik, subjek melakukan rally lagi 30 detik.

\section{Petunjuk penskoran:}

a. Penskoran dilakukan 3 orang, 1 orang pencatat, 1 orang pemegang stopwatch, dan 1 orang mengamati bola masuk sasaran.

b. Bola yang masuk sasaran $30 \mathrm{~cm}$ persegi bernilai 5, dan bola yang masuk sasaran daerah $60 \mathrm{~cm}$ persegi diberi nilai 3 , bola yang tidak masuk sasaran sisanya bernilai 1 .

c. Bola pertama dari testi tidak dicatat atau tidak dihitung.

d. Pencatat menjumlah skor setiap rally selama 30 detik.

e. Jumlah skor tertinggi dari rally selama 30 detik yang dipakai.

\section{Tempat}

Lokasi penelitian Lapangan Pade Angen beralamat di rembige Mataram, Waktu Pelaksanaan penelitian direncanakan selama 6 minggu (3 kali dalam semiggu).Hari Senin, Rabu, dan Jum'at, Jam 16.00 - 18.00.

\section{Teknik penumpulan data}

Dalam penelitian ini metode yang digunakan untuk memperoleh data tersebut adalah metode dokumentasi, dan metode tes perbuatan.

\section{Teknik Observasi}

Observasi merupakan suatu metode pengumpulan data, observasi diartikan sebagai suatu proses yang kompleks, suatu proses yang tersusun dari berbagai proses biologis dan pshikologis (Sugiyono, 2013: 203).

\section{Metode Tes Perbuatan}

Tes adalah suatu cara untuk mengadakan penelitian terhadap suatu subyek atau obyek-obyek tertentu untuk mendapatkan data secara cepat dan tepat Arikunto, (2006 :44). Dalam penelitian ini, menggunakan tes kelincahan.

\section{Teknik Dokumentasi}

Teknik dokumentasi dalam penelitian ini digunakan untuk memperoleh data melalui catatan yang bersifat kuantitatif, data ini dapat bersifat pribadi atau pengalaman yang ditulis oleh subjek, 
data yang diperoleh dari pengamatan langsung yang diperkuat oleh peneliti dengan menggunakan teknik dokumentasi dalam mengumpulkan data.

Dokumentasi diperlukan dalam penelitian kuantitatif, karena menghasilkan deskriptif yang berharga dan digunakan untuk mengolah segi-segi subjektif dan hasil yang dianalisa secara induktif.

\section{Difinisi operasional variable}

\section{a) Latihan}

Latihan adalah suatu proses mempersiapkan fisik dan mental anak latih secara sistematis untuk mencapai mutu prestasi yang optimal dengan diberikan beban latihan yang teratur, terarah, meningkat, dan berulangulang waktunya".

b) latihan multiball

Metode latihan ini menekankan pada frekuensi pemukulan, sehingga memungkinkan siswa untuk membiasakan diri memukul bola ke sasaran yang dituju, sehingga gerakan siswa tersebut menjadi otomatisasi. Metode multiball bisa juga menggunakan mesin ataupun manual yang diberi oleh pelatih atau pengumpan.

c) Smash Forehand

Pukulan forehand merupakan pukulan utama dalam permainan tenis meja.

\section{d) Tenis Meja}

permainan tenis meja adalah permainan dengan menggunakan fasilitas meja beserta peralatannya serta bet dan bola sebagai alatnya". Permainan ini diawali dengan pukulan pembuka (service), yaitu bola dipantulkan ke meja sendiri lalu melewati atas net dan memantul di meja lawan sampai lawan tidak dapat mengembalikan dengan baik

\section{Teknik analisa data}

Untuk memperoleh satu kesimpulan masalah yang di teliti, maka analisis data merupakan satu langkah penting dalam penelitian. Sesuai dengan rumusan masalah dan tujuan penelitiannya maka analisis data yang digunakan dalam penelitian ini adalah $t$-test dengan rumus : Maka digunakan analisis statistik dengan rumus sebagai berikut Hulfian, (20014: 71).

$$
t=\frac{\sum D}{\sqrt{\frac{N \cdot \sum D^{2}-\left(\sum D\right)^{2}}{(N-1)}}}
$$

Keterangan:

$\mathrm{D}=$ Perbedaan setiap pasangan skor (post test-pre test)

$\mathrm{N}=$ Jumlah sampel yang digunakan

Adapun langkah-langkah menganalsis data adalah sebagai berikut:

1. Merumuskan hipotisis

2. Menyusun table kerja (table persiapan)

3. Mendistribusikan data kedalam rumus

4. Menguji nilai $\mathrm{T}$

5. Menarik kesimpulan

\section{HASIL DAN PEMBAHASA}

\section{Merumuskan Hipotesis nihil (Ho)}

Untuk menguji hipotesis alternatif (Ha) berbunyi : Ada Pengaruh latihan multiball terhadap keterampilan smash forehand tenis meja pada Club Pade Angen Mataram tahun 2020". Maka harus diubah menjadi hipotesis nol (Ho) yang berbunyi: Tidak Ada Pengaruh latihan multiball terhadap keterampilan smash forehand tenis meja pada Club Pade Angen Mataram tahun 2020".

\section{Menyusun tabel kerja}


Tabel 1.1 Tabel kerja untuk mencari nilai" t" keterampilan smash forehand tenis meja pada Club Pade Angen Mataram tahun 2020

\begin{tabular}{|c|c|c|c|c|c|}
\hline No & Nama Pemain & $\mathrm{Xl}$ & $\mathrm{X} 2$ & $\begin{array}{c}\mathrm{D}(\mathrm{X} 1- \\
\mathrm{X} 2)\end{array}$ & $\mathrm{D} 2$ \\
\hline 1 & Abdul Majid & 19 & 19 & 0 & 0 \\
\hline 2 & Dedi Pranata & 20 & 22 & 2 & 4 \\
\hline 3 & Achmad Marwan & 21 & 23 & 2 & 4 \\
\hline 4 & Ahmad Fauzzi & 18 & 18 & 0 & 0 \\
\hline 5 & Ahmad Fauzan & 19 & 20 & 1 & 1 \\
\hline 6 & Gigih Pashu & 18 & 20 & 2 & 4 \\
\hline 7 & Yoga Satria & 18 & 18 & 0 & 0 \\
\hline 8 & Sopian Wiranadi & 17 & 19 & 2 & 4 \\
\hline 9 & Hoalan & 18 & 19 & 1 & 1 \\
\hline 10 & Ahmad Sigit Tri Putra & 19 & 21 & 2 & 4 \\
\hline 11 & Baym Andira Saputra & 16 & 17 & 1 & 1 \\
\hline \multirow[t]{3}{*}{12} & Sukma Bayu Segara & 19 & 20 & 1 & 1 \\
\hline & $\sum$ & 222 & 236 & 14 & 24 \\
\hline & & 18.5 & 19.6667 & 1.1666667 & 2 \\
\hline
\end{tabular}

3. Mendistribusikan data kedalam rumus

Pada langkah ini data yang sudah tercantum dalam tabel $4.6 \mathrm{di}$ atas kemudian dimasukkan kedalam rumus " $t$-test" sebagai berikut :

$$
\begin{aligned}
& t=\frac{\sum D}{\sqrt{\frac{N \cdot \sum D^{2}-\left(\sum D\right)^{2}}{(N-1)}}} \\
& t=\frac{24}{\sqrt{\frac{12.14-24}{(12-1)}}} \\
& t=\frac{24}{\sqrt{\frac{168-576}{(11)}}}
\end{aligned}
$$

$$
\begin{aligned}
t & =\frac{24}{\sqrt{\frac{408}{11}}} \\
t & =\frac{24}{\sqrt{36.818}} \\
t & =\frac{24}{6.067} \\
t & =3.955
\end{aligned}
$$

$$
\begin{aligned}
\text { Peningkatannya } & =\frac{M d}{M p r e} \times 100 \\
& =\frac{2}{18.5} \times 100 \\
& =10.81 \%
\end{aligned}
$$

\section{Menguji nilai (t)}

Setelah mendapatkan t-hitung diperoleh nilai sebesar 10.30 kemudian $\mathrm{t}$-tabel dengan derajat kebesaran $\mathrm{N}-1$ $=11$ pada taraf signifikan 5\% menunjukan angka yaitu 1.796. Hasil ini berarti bahwa t- hitung > t-tabel, yaitu (3.995 > 1.796) atau dengan kata lain t-hitung yang diperoleh lebih besar dari angka batas penolakan hipotesis nihil (Ho) diperlukan nilai t-hitung sama atau lebih besar dari nilai t-tabel..

\section{Menarik Kesimpulan}

Dengan analisis data yang signifikan, maka dengan dasar ini hipotesis nihil (Ho) ditolak dan hipotesis alternatif $(\mathrm{Ha})$ diterima $\mathrm{N}-1$ $(12-1)=11$. Berdasarkan uraian diatas peneliti dapat menyimpulkan bahwa : Berdasarkan kenyataan di atas yaitu thitung lebih besar dari t-tabel, dengan demikian nilai $\mathrm{t}$ yang diperoleh dalam penelitian ini signifikan, (Berpengaruh). Ha (diterima) ada Pengaruh latihan multiball terhadap keterampilan smash forehand tenis meja pada Club Pade Angen Mataram tahun 2020"., Ho (ditolak) tidak ada Pengaruh latihan multiball terhadap keterampilan smash forehand tenis 
meja pada Club Pade Angen Mataram tahun 2020.

\section{Pembahasan}

Menurut hasil penelitian dan pengamatan menunjukan bahwa Latihan Pengaruh latihan multiball terhadap keterampilan smash forehand tenis meja pada Club Pade Angen Mataram tahun 2020, Membantu memperbaiki keterampilan smash forehand. Kemampuan ketepatan forehand drive sangat dipengaruhi oleh beberapa faktor diantaranya denga metode latihan yang baik dan benar. Dengan memilih metode yang tepat dan sesuai dengan kemampuan atletnya, kemampuan ketepatan forehand drive dapat meningkat. Kemampuan ketepatan forehand drive yang baik sendiri dipengaruhi oleh frekuensi dan kualitas latihan baik. Dari segi frekuensi latihan, dapat disimpulkan bahwa dengan latihan yang terprogram dan waktu yang lama, maka peningkatan ketepatan mahasiswa dapat terus meningkat. Artinya makin sering pada pemain pada Club Pade Angen mendapat latihan suatu ketepatan, maka makin matang tepat mengarahkan ke sasaran.

\section{KESIMPULAN}

Berdasarkan analisa data, memberikan kesimpulan bahwa "Pengaruh latihan multiball terhadap keterampilan smash forehand tenis meja pada Club Pade Angen Mataram tahun 2020”. Keadaan ini didukung oleh analisa t-test yang menghasilkan t-hitung lebih besar dari pada t-tabel $(3.995>1.796)$ sehingga hipotesis Nol (Ho) ditolak Tidak Ada Pengaruh latihan multiball terhadap keterampilan smash forehand tenis meja pada Club Pade Angen Mataram tahun 2020". Ha diterma, ada Pengaruh latihan multiball terhadap keterampilan smash forehand tenis meja pada Club Pade Angen Mataram tahun 2020

\section{SARAN}

Berdasarkan hasil analisa data, pembahasan, dan kesimpulan di atas maka dapat diberikan saran dan tindak sebagai berikut, Kepada pemai Timbulnya semangat dari tenis meja pada Club Pade Angen Mataram tahun 2020 untuk meningkatkan kemampuan ketepatan forehand drive.

Kepada Pelatih

Dalam rangka peningkatan dan pengembangan prestasi atlet maka faktor yang sangat perlu diperhatikan oleh seorang pelatih adalah memberikan latihan secara kontinyu. Timbulnya inisiatif dari pelatih untuk menerapkan latihan multiball dengan tujuan untuk meningkatkan kemampuan ketepatan forehand drive.

Kepada orang tua

Hendaknya orang tua membantu mengembangkan bakat yang dimiliki oleh putranya yang dan penelitian ini dapat dijadikan sebagai bahan masukan maupun perbandingan, jika peneliti ingin mengangkat masalah yang sejenis dengan penelitian ini

\section{DAFTAR PUSTAKA}

Arikunto, Suharsimi. 2006. Manajemen Penelitian, Jakarta: Rineka Cipta

Arikunto, Suharsimi. 2013. Manajemen Penelitian, Jakarta: Rineka Cipta

Bompa, Tudor O. (1994). Theiry and Methodologi of Training. lowa: Kendal/Hunt Publishing Company.

Hulfian, L. 2014. Statistik Dikjas. Mataram: GENIUS.

Hulfian, L. 2014. Kondisi Fisik Dan Tes Pengukuran Dalam Olahraga. Lembaga Penelitian dan Pendidikan (LPP) Mandala. 
Hulfian, L. 2014. Penelitian Dikjas. CV. Garuda Ilmu.

Hodges, L. (1996). Table tennis: steps to success (Tenis Meja: tingkat pemula). Penerjemah Eri D. Nasution. Jakarta: PT Raja Grafindo Persada. Kertamanah, A. (2003). Teknik dan Taktik Dasar Permainan Tenis Meja. Jakarta: PT RajaGrafindo Persada

Kemenegpora. 2009. Materi Pelatihan Pelatih Fisik Level II. Asdep Pengembangan Tenaga dan Pembinaan Keolahragaan.

Maksum, A. 2009. Metodologi Penelitian Dalam Olahraga. Surabaya: FIK Universitas Negeri Surabaya,

Maksum, A.2012 Metodologi Penelitian Dalam Olahraga. Surabaya: FIK Universitas Negeri Surabaya.

Mylsidayu dan Kurniawan. 2015. Kepelatihan Olahraga. Jakarta : PT Persada.University Press.

Muhtar, T. \& Sulistyo, W. (2005). Tenis Meja (Modul Mata Kuliah Pilihan 1). Jakarta: Universitas Terbuka

Nurhasan. 2001. Prinsip-Prinsip dan Penerapannya. Jakarta : Direktorat Jenderal Olah Raga.

Roesdiyanto dan Budiwanto, S. 2008. Dasar - Dasar Kepelatihan Olahraga. Malang: Laboratorium Ilmu Keolahragaan Jurusan Ilmu Keolahragaan Universitas Negeri Malang.

Salim, A. (2008). Buku Pintar Tenis Meja. Bandung: Nuansa.

Sajoto, M.(1988). Pembinaan Kondisi Fisik dalam Olahraga, Jakarta, Departemen Pendidikan dan Kebudayaan.

Sugiyono. 2010. Metode Penelitian Pendidikan (Pendekatan Kuantitatif, Kualitatif, dan $R \& D)$. Bandung : Alfabeta.
Suhamo HP. (1983). Ilmu Coaching Umum. Yogyakarta: FPOK IKIP Yogyakarta. Suharno H.P. (1980). "Metodik Melatih Permainan Bola Volly". Yogyakarta. IKIP Yogyakarta

Sugiyono. 2013. Metode Penelitian

Pendidikan (Pendekatan Kuantitatif, Kualitatif, dan $R \& D)$. Bandung :

Alfabeta

Sukadiyanto. 2005. Pengantar Teori dan Metodologi Melatih Fisik. Bandung : Lubuk Agung.

Syafruddin. 2011. Ilmu Kepelatihan Olahraga. Padang, FIK.UNP.

Tomoliyus. (2012). Sukses melatih keterampilan Dasar Permainan Tenis meja dan Penilaian. Disajikan dalam Rangka Pembinaan Klub Olahraga Sekolah Dasar Se- Indonesia Tahap II Di Yogyakarta.

Tangkudung. 2012. Kepelatihan Olahraga" Pembinaan Prestasi Olahraga" Edisi II. Jakarta: Cerdas Jaya.

Utama, A.M.B. (2005). "Kemampuan Bermain Tenis Meja, Studi Korelasi Antar Kelincahan dan Kemampuan Pukulan dengan Kemampuan Bermain Tenis Meja". Laporan Penelitian. Yogyakarta: FIK UN 